\title{
Psychological determinants of infantile pyloric stenosis
}

\author{
SUSAN I. REVILL and J. A. DODGE \\ From the Department of Child Health, Welsh National School of Medicine, Cardiff
}

SUMMARY In order to investigate the possible contribution of maternal emotional stress to the aetiology of infantile pyloric stenosis, 100 mothers of affected infants, 100 'normal' controls who had not sought medical advice at any time concerning feeding problems, and 50 mothers of children with spina bifida were interviewed. All completed the Life Events Inventory, which gives a quantitative measurement of stressful life events during a given period. In addition, the subject mothers and 'normal' controls completed form A of the Eysenck Personality Inventory, the Multiple Affect Adjective Check list, and Linear Analogue Scales for the subjective measurement of satisfaction with feeding and distress caused by feeding problems.

A highly significant difference was found between the number of items given a heavy weighting on the Life Events Inventory experienced by the subjects and both control groups. This was particularly marked during the last trimester of pregnancy. Personality assessment was very similar in all groups, but maternal anxiety scores were higher in the subjects than in the controls. It is concluded that hypertrophic pyloric stenosis occurs unduly frequently in infants of normal mothers who have been subjected to particularly stressful events during pregnancy.

Previous studies of infantile pyloric stenosis have frequently noted that there is a higher incidence of this condition among first-born infants than would be expected (McKeown et al., 1951; Shim et al., 1970; Dodge, 1975). Since the first pregnancy obviously has greater emotional impact on the mother than subsequent pregnancies, it has been suggested that prenatal emotional stress may act, perhaps by a humoral pathway, in such a way that the fetus is rendered more liable to develop pyloric hypertrophy.

It has also been reported that there is a high incidence of significant emotional stress during the last trimester of pregnancy in women giving birth to a child with pyloric stenosis. In that study mothers were asked to recall any worries while they were pregnant, and analysis of the data showed a remarkably high incidence of stress, greatly exceeding the incidence in the control subjects. Of 101 matched pairs, $\mathbf{4 2}$ of the mothers of affected babies stated that they had experienced stressful events during the last trimester of pregnancy, compared with only 8 of the controls (Dodge, 1972).

The purpose of the present study was to investigate further the role of prenatal emotional stress in mothers of infants with pyloric stenosis, using the Received 15 May 1977.
Life Events Inventory (LEI) as a standardised measure of stress.

\section{Materials and methods}

The LEI is a checklist used to measure the relative severity of psychosocial stressors. It is a development of the Schedule of Recent Experiences which has been widely used as a psychological tool for the retrospective measurement of life stresses. Each of the 55 events on the inventory is assigned a weighting which reflects the degree of 'turmoil, disturbance, and upheaval' that would be caused should that event befall an average person. Not all the events will necessarily be accompanied by negative effect. For example, items such as 'Marriage' and 'Going on Holiday' are, presumably, pleasant events, while others such as 'Moving House', 'New Job in New Line of Work', and 'Pregnancy' may be either pleasant or unpleasant, or even neutral, events. Weights for the items of the LEI were assigned ty groups likely to have experience of the events involved, namely psychologists, psychiatrists, psychiatric patients, and students. Examples of high weighted items include 'Death of Spouse' (86), 'Divorce' (75), and 'Jail Sentence' (75) (Cochrane and Robertson, 1973). 
The LEI can be used both as a supplement to the clinical interview and as a standardised measure of the amount of stress that has been present in a person's immediate environment in the preceding year. For the purpose of this study, LEI items were termed 'weighted' if they had been given a weighting of 60 or over in the standardisation procedure.

The subjects were 100 mothers of children who had undergone surgery for hypertrophic pyloric stenosis ('subject mothers'). They were interviewed while attending a special research follow-up clinic and had been contacted by personal letter some months or years after their child's illness. A comparison group consisted of 100 randomly selected mothers of children born at the maternity unit, University Hospital of Wales ('normal controls'). None had sought medical advice at any time concerning feeding problems. They were interviewed in their own homes as part of the follow-up to another perinatal study.

All subjects and controls lived in the Cardiff area of South Wales. None of the mothers approached refused to co-operate with the study. In addition to the LEI, psychological assessment of the mothers was carried out using the Eysenck Personality Inventory, form A; the Multiple Affect Adjective Check List; and Linear Analogue scales for the subjective measurement of satisfaction with feeding and distress caused by feeding problems (Revill et al., 1976).

In the main study the LEI, personality and mood tests, and rating scales of feeding difficulties and distress were administered to all 3 groups of mothers by one investigator (S.R.). The subject mothers were first asked if they were at all upset by any feeding problems during the period between birth and onset of symptoms, and were instructed to rate the degree of distress or satisfaction with feeding behaviour on linear analogues. The same procedure was followed with the 'normal control' mothers with respect to satisfaction or distress concerning infant feeding during the first 3 weeks of life.

The subject mothers and the normal controls were then instructed to complete the LEI by putting a tick against any of the events which happened to them during their pregnancy. On completion of the LEI they were asked to specify the month of their pregnancy in which any events they had ticked had occurred. Finally, both groups were asked to complete the Eysenck Personality Inventory, form A, and the Multiple Affect Adjective Check List.

In order to allow for the possibility that the subject group might have been motivated to remember more details of the pregnancy which resulted in an affected child, the LEI was also administered to a group of 50 mothers of children born with spina bifida, a condition which is known to be present early in gestation and is therefore not caused by subsequent events during pregnancy. These mothers were randomly selected on attendance at the spina bifida clinic, Cardiff Royal Infirmary ('spina bifida controls'), and were required to complete only the LEI.

The mean ages of the groups at the time of birth were: subject mothers $24 \cdot 8$ years, normal controls $26 \cdot 7$ years, spina bifida controls $24 \cdot 3$ years. There was no significant difference between any of these mean ages. The subject mothers were interviewed on average 4.9 years after the birth of the infant, the range being 6 months to 13 years; the spina bifida controls were interviewed on average 5.4 years after the birth, the actual age range of the children being 6 months to 15 years; whereas the normal controls were subjects in another on-going study, so the average interval between birth and interview was only 6 months.

There was no significant difference between the mean age of the children of the subject group and that of the spina bifida control group. It was thought that despite the greater interval between birth of the affected children in these two groups and the time of interview compared with the normal control group, this should not seriously affect maternal recollection of the 'weighted' life events; and that if any effect were produced it would be in the direction of failure to remember incidents and thus would tend to negate the original hypothesis, that stress plays a role in the aetiology of pyloric stenosis.

\section{Results}

Approximately $80 \%$ of the mothers in all groups had experienced at least one item on the LEI during pregnancy, but when only the 'weighted' events were considered, $44 \%$ of subject mothers had experienced at least one such event compared with $34 \%$ of spina bifida controls, and only $26 \%$ of normal controls (Table 1). There was no significant difference

Table 1 Percentage of mothers who had experienced at least one 'weighted' item

\begin{tabular}{lll}
\hline Subject mothers & (A) & 44 \\
Spina bifida controls & (B) & 34 \\
Normal conirols & (C) & 26 \\
\hline
\end{tabular}

$A: B=N S ; B: C=N S ; A: C=N S$.

between the total number of events on the LEI experienced by all three groups, either throughout the entire pregnancy or during the last trimester of the pregnancy.

However, when the number of 'weighted' events which occurred throughout the entire pregnancy was considered the subject mothers had experienced 
three times as many as the normal controls, and twice as many as the spina bifida controls (Table 2). This difference became more obvious when only the last trimester of pregnancy was considered, when the subjects experienced almost four times as many 'weighted' items as the normal controls, and almost three times as many as the spina bifida controls (Table 3). Another interesting difference was found between the scores of the subject mothers and the normal controls on the Anxiety Scale of the Multiple Affect Adjective Check List $(\mathrm{P}<0 \cdot 00001)$ (Table 4).

Table 2 Mean number of 'weighted' events during entire pregnancy

\begin{tabular}{lll}
\hline Subject mothers & (A) & 0.74 \\
Spina bifida controls & (B) & 0.42 \\
Normal controls & (C) & 0.27 \\
\hline
\end{tabular}

$\mathrm{A}: \mathrm{B}, \mathrm{P}<0.02 ; \mathrm{A}: \mathrm{C}, \mathrm{P}<0.0001 ; \mathrm{B}: \mathrm{C}=\mathrm{N} . \mathrm{S}$.

Table 3 Mean number of 'weighted' items during last trimester

$\begin{array}{lll}\text { Subject mothers } & \text { (A) } & 0.5 \\ \text { Spina bifida controls } & \text { (B) } & 0.2 \\ \text { Normal controls } & \text { (C) } & 0.13\end{array}$

$\mathrm{A}: \mathrm{B}, \mathrm{P}<0.01 ; \mathrm{A}: \mathrm{C}, \mathrm{P}<0.0001$.

Table 4 Multiple affect adjective check list anxiety scale

\begin{tabular}{llll}
\hline & Subjects $(n=100)$ & 'Normal' controls $(n=100)$ \\
\hline Mean & 7.99 & 6.3 & \\
SD & 2.73 & $2.45 \quad$ P $<0.00001$ \\
SE & 0.27 & 0.24 & \\
\hline
\end{tabular}

However, there was no significant difference between the scores of subject mothers and normal controls on the neuroticism scale of the Eysenck Personality Inventory nor on the extroversion scale. In each case the mean scores were very similar and normal.

Finally, there were no significant differences in the mean percentage ratings between the subject mothers and normal controls for satisfaction and distress concerning feeding. This indicates that before the onset of projectile vomiting in the affected babies, their mothers showed no more evidence of anxiety than the normal controls.

\section{Discussion}

An important point which emerges from these results concerns the personality dimensions of neuroticism and extroversion measured by the Eysenck Personality Inventory, where there were no significant differences between the subjects and normal controls. This is a strong indication that the subjects were 'normal' individuals who could be expected to react in a 'normal' way to a stressful situation. It emphasises the observation of the increased number of 'weighted' events occurring during the pregnancies, and particularly during the last trimester, of the subjects compared with the 'normal' controls. The situation revealed is therefore not one of neurotic individuals over-reacting to everyday events, but of normal people reacting to particularly stressful events.

The fact that the subject mothers experienced a significantly greater number of 'weighted' events than the spina bifida controls implies that the excess of stressful events is unlikely to be due to a general tendency for mothers of children born with an abnormality to attribute the condition to some untoward event in pregnancy.

The subject mothers were significantly more anxious than the controls during the interview. We interpret the heightened anxiety scores of the subject mothers as possibly being due to the circumstances of the interview. They were seen in a special clinic which was probably more threatening than the home environment in which the normal controls were seen. This difference of circumstance should not, however, have any effect on the LEI results.

We therefore conclude that normal mothers who have been subjected to an increased number of particularly stressful events during pregnancy have an increased risk of giving birth to a child with hypertrophic pyloric stenosis. This observation supports the hypothesis that excessive stress during pregnancy might be a contributory factor in the aetiology of pyloric stenosis, possibly by means of a humoral agent.

\section{References}

Cochrane, R., and Robertson, A. (1973). The life events inventory: a measure of the relative severity of psychosocial stressors. Journal of Psychosomatic Research, 17, 135-139.

Dodge, J. A. (1972). Psychosomatic aspects of infantile pyloric stenosis. Journal of Psychosomatic Research, 16, $1-5$.

Dodge, J. A. (1975). Infantile hypertrophic pyloric stenosis in Belfast, 1957-1967. Archives of Disease in Childhood, 50, 171-178.

McKeown, T., MacMahon, B., and Record, R. G. (1951). Incidence of congenital pyloric stenosis related to birth rank and maternal age. Annals of Eugenics, 16, 249-259.

Revill, S. I., Robinson, J. O., Rosen, M., and Hogg, M. I. J. (1976). The reliability of a linear analogue for evaluating pain. Anaesthesia, 31, 1191-1198.

Shim, W. H. T., Campbell, A., and Wright, S. W. (1970). Pyloric stenosis in the racial groups of Hawaii. Journal of Pediatrics, 76, 89-93.

Correspondence to Dr J. A. Dodge, Department of Child Health, Welsh National School of Medicine, Heath Park, Cardiff CF4 4XN. 